\title{
Desain Pengembangan Kerjasama Kelembagaan dalam Peningkatan Profesionalisme Civitas Akademika di Fakultas Ilmu Tarbiyah Dan Keguruan (FITK) IAIN Surakarta
}

\author{
Muhammad Munadi \\ IAIN Surakarta \\ munadimahdiputra@gmail.com \\ Retno Wahyuningsih \\ IAIN Surakarta \\ retnowahyuningsih2008@gmail.com \\ Khuriyah \\ IAIN Surakarta \\ khuriyah98@gmail.com
}

\begin{abstract}
This research aims to understand the reality of cooperation management, the reality of cooperation development and development design of institutional cooperation on the improvement of civitas academic professionalism in IAIN Surakarta. This study was located in Faculty of Education and Teacher Training since it has a lot of spaces for profession development, especially a space for Field Experience Practice program that nearly covers madrasah/schools in Surakarta, a space for Fieldwork Study, and madrasah/schools empowerment activity. The subject of this research is 4 heads of department, 3 heads of deanship and 3 rectorate officials. Data collection technique is using interview, observation, and documentation. Data validity technique is using source and method triangulation. Data analysis is using interactive analysis model. The result of this research shows that: The reality of cooperation management is still "top down" when it is related to the draft planning of collaboration paper. The reality of cooperation development which was started from cooperation without legal protection develops into the one with legal protection. Cooperation development design is developed through user mapping, strengthen the cooperation with school partners which focuses not only on PPL implementation but also on "give and take" activity which has yet happened between madrasah/schools and faculties in IAIN Surakarta.
\end{abstract}

Keywords: Cooperation, Development, Professionalism

\section{Article Info}

Received date: 8 Mei 2019

Revised date: 25 Juni 2019

Accepted date: 25 Juni 2019

\section{PENDAHULUAN}

Beberapa perguruan tinggi di Indonesia saat ini telah mempunyai dan menyelenggarakan program kerjasama pendidikan, baik antara perguruan tinggi nasional maupun bermitra dengan perguruan tinggi dari luar negeri. Kerjasama pendidikan yang dilaksanakan oleh perguruan tinggi tersebut mempunyai bentuk dan mekanisme yang beragam, mulai dari bentuk program dual 
degree, kembaran, hingga mekanisme feeder. Namun demikian sejauh ini kerjasama pendidikan antara perguruan tinggi tersebut belum berlandaskan suatu kebijakan dan/atau ketentuan baku yang mampu memberikan jaminan kualitas layanan pendidikan bagi masyarakat.

Kerjasama antar perguruan tinggi atau lembaga lain baik dalam maupun luar negeri telah diatur dengan jelas dalam pasal 122 ayat (1) Peraturan Pemerintah Nomor 30 Tahun 1990. Pasal tersebut memberikan legitimasi pentingnya jalinan kerjasama perguruan tinggi dalam rangka peningkatan dan pengembangan kualitas serta pengembangan institusional sebuah perguruan tinggi secara keseluruhan.

Selain itu, pada hakikatnya kerjasama merupakan upaya memecahkan isolasi institusional yang dihadapi perguruan tinggi, baik pada level lokal, nasional, regional, maupun internasional, terutama dalam upaya peningkatan mutu akademik masing-masing perguruan tinggi. Lingkup kerjasama tersebut pada umumnya dalam bentuk afiliasi atau bantuan tenaga ahli, lembaga kajian, beasiswa atau bantuan sarana dan prasarana belajar mengajar.

$$
\text { World Declaration On Higher }
$$

Education For The Twenty-First Century: Vision And Action (Unesco, 1998) menyebut tentang pentingnya kerjasama, kemitraan, dan aliansi pada dua poin penting. Dua poin tersebut, yaitu: Article 7 - Strengthening cooperation with the world of work and analyzing and anticipating societal needs dan Article 17 - Partnership and alliances. Dua artikel tersebut menujukkan pentingnya perguruan tinggi membuat terobosan kaitannya dengan profesionalitas sivitas akademikanya.

Direktorat Jendral Pendidikan Tinggi menyusun strategi Pengembangan Pendidikan Tinggi Jangka Panjang (Higher Education Long Term Strategy, HELTS) 2003-2010. Kata kunci dari strategi tersebut adalah penempatan perguruan tinggi sebagai kunci untuk memperkuat daya saing bangsa melalui peningkatan mutu pendidikan tinggi agar mampu mengembangkan potensi mahasiswa secara optimal. Hal ini dibenarkan Goetsch dan Davis (2006: 143) bahwa kerjasama dan kemitraan dapat mengembangkan mutual benefit yang menjadi dasar kualitas menyeluruh sebuah lembaga. Kemitraan dan kerjasama antar perguruan tinggi dan lembaga didorong untuk menciptakan sinergi yang sehat dan kompetitif. Melalui kerjasama dan kemitraan tersebut diharapkan akan terjadi resource sharing di antara lembaga dengan perguruan tinggi yang berkolaborasi.

Kerjasama memiliki kerangka memenuhi kebutuhan dalam masyarakat untuk berpikir dan bekerja sama dalam isu-isu kritis telah meningkat (Austin 2000a; Welch 1998). Melihat tersebut kemitraan, kerjasama dan kolaborasi merupakan hal yang sangat urgen dalam pendidikan.

Kemitraan, kerjasama ataupun kolaborasi menjadi penting bagi pendidikan terutama perguruan tinggi dikarenakan tugas pendidikan merupakan tugas yang sangat besar dan kompleks, pendidikan merupakan usaha multi-fungsional karena tidak hanya mengurusi pembelajaran saja, melemahnya sistem dukungan tradisional pada pendidikan, pendidikan dan "mitra" lainnya memiliki kegiatan yang sama, memanfaatkan sumber daya dan keahlian dalam keuangan akan terjadi ketika ada kemitraan yang efektif, dan mandat eksternal membutuhkan kemitraan (Aka, 1993:2).

Dalam konteks IAIN Surakarta, organisasi tata kerjanya telah ada dua lembaga yang mengurusi kerjasama, yaitu Wakil Rektor bagian Kemahasiswaaan dan Kerjasama dan Sub Bagian Kemahasiswaan dan Kerjasama. Dua lembaga ini diharapkan bisa menjadi garda terdepan dalam meningkatkan kapasitas kelembagaan di bidang keilmuan.

Tulisan ini akan membahas realitas pengelolaan kerjasama dengan dunia eksternal 
dalam rangka peningkatan profesionalitas sivitas akademika selama ini di tingkat program studi, realitas pengembangan kerjasama dengan dunia eksternal dalam rangka peningkatan professionalitas civitas akademika di IAIN Surakarta selama ini dan desain pengembangan kerjasama kelembagaan dalam rangka peningkatan professionalitas civitas akademika di IAIN Surakarta.

Kemitraan, kerjasama ataupun kolaborasi menjadi penting bagi pendidikan terutama perguruan tinggi dikarenakan tugas pendidikan merupakan tugas yang sangat besar dan kompleks, pendidikan merupakan usaha multi-fungsional karena tidak hanya mengurusi pembelajaran saja, melemahnya sistem dukungan tradisional pada pendidikan, pendidikan dan "mitra" lainnya memiliki kegiatan yang sama, memanfaatkan sumber daya dan keahlian dalam keuangan akan terjadi ketika ada kemitraan yang efektif, dan mandat eksternal membutuhkan kemitraan (Aka,1993: 2).

Kerjasama (cooperation), Kemitraan (partnership), dan kolaborasi (collaboration) merupakan istilah yang saling menggantikan (inter-chageability), sehingga teori yang dibangun dalam kajian inipun juga dipakai tiga istilah tersebut secara bergantian. Pendapat berbeda dinyatakan Czajkowski (2007: 1) dengan memasukkan koordinasi dengan menghilangkan istilah partnership : Three relationship processes are identified in the literature on inter-organizational relationships: cooperation, coordination, and collaboration. Kerjasama (cooperation), kemitraan (partnership), dan kolaborasi (collaboration) dan koordinasi (coordination) merupakan bentuk hubungan interorganizational. Hal tersebut diungkap juga dalam The Oxford Dictionary (Bailey dan Dolan, 2011) yang mendefinisikan: partnership in terms of a relationship between people or organizations. Other associated words include association, cooperation, collaboration, participation, joint decision making and long-term relationship. Pendapat tersebut menunjukkan adanya kesamaan antara istilah kerjasama (cooperation), kemitraan (partnership), dan kolaborasi (collaboration) dan koordinasi (coordination) dalam hubungan dengan organisasi lain. Keempat istilah ini merupakan adopsi dari konsep ekonomi bisnis.

Prinsip dalam kerjasama harus bersifat satu koordinat bukan sub-ordinat serta bersinergi yang mengatur segala aspek operasional PT, sehingga bisa merealisir semangat dari peraturan yang ada yaitu sesuai dengan prinsipnya: kesetaraan, saling menghormati, dan saling menguntungkan. Koordinat yang sama menjadikan aturan ini lebih menegaskan tentang kerjasama di semua bidang pada perguruan tinggi.

Himmelman. (1996) mendefinisikan kooperasi sebagai exchanging information, altering activities, and sharing resources for mutual benefit and to achieve a common purpose. Cooperation requires even greater organizational commitments and, in some cases, may involve legal arrangements. Shared resources can encompass a variety of human, financial, and technical contributions, including knowledge, staffing, physical property, access to people, money, and others.

A. Martínez Gonzalez-Tablas yang dikutip Beneitone (2003:10) menyatakan:

To co-operate implies sharing work or a task, doing something with others in a coordinated way, in conformity with a plan, and to a certain degree, voluntarily, encouraged by some type of mutual interest or benefit, which may be established as well between unequal partners, as between equals.

Pendapat tersebut bermakna untuk bekerja sama menyiratkan berbagi pekerjaan atau tugas, melakukan sesuatu dengan orang lain dalam cara yang terkoordinasi, sesuai dengan rencana, dan untuk tingkat tertentu, secara sukarela, didorong oleh beberapa jenis kepentingan bersama atau manfaat, yang dapat 
didirikan juga antara mitra yang tidak setara, seperti antara yang setara.

Edwards yang dikutip Vasilyan (2004 :2) menyatakan: ..proposes that 'cooperation implies reciprocity (not complete equality), a willingness to give as well as take, the voluntary acceptance of limits on all sides rather than one'. Pendapat tersebut menunjukkan bahwa kerjasama menyiratkan timbal balik, kemauan untuk memberikan serta menerima, penerimaan sukarela dari batas di semua sisi bukan dari satu sisi.

Dalam konteks pengembangan kerjasama perguruan tinggi Wannie etal yang dikutip Bailey \& Dolan (2011) menyatakan tentang kemitraan sebagai berkut:

"...a dynamic collaborative process between educational institutions that brings mutual though not necessarily symmetrical benefits to the parties engaged in the partnership. Partners share ownership of the projects. Their relationship is based on respect, trust, transparency and reciprocity. They understand each other's cultural and working environment. Decisions are taken jointly after real negotiations take place between the partners. Each partner is open and clear about what they are bringing to the partnership and what their expectations are from it. Successful partnerships tend to change and evolve over time".

Definisi tersebut mengartikan kemitraan dalam konteks pengembangan kerjasama perguruan tinggi adalah proses kolaboratif dinamis antara institusi pendidikan yang saling membawa manfaat yang didasarkan pada rasa hormat, kepercayaan, transparansi, dan timbal balik. Mereka memahami masing-masing budaya yang dan lingkungan kerja. Keputusan diambil bersamasama setelah negosiasi yang nyata terjadi antara para mitra. Setiap pasangan terbuka dan jelas tentang apa yang mereka bawa ke kemitraan dan harapan mereka. Kemitraan yang sukses cenderung untuk berubah dan berkembang dari waktu ke waktu ".

Pendapat lain dinyatkan Beneitone (2003:9) yang mengutip The Development Aid Committee of the Organization for Economic Co-operation and Development (OECD) defines international cooperation as a broad concept that encompasses all kinds of activities carried out jointly and in coordination by two or more sovereign States and/or by these and international organizations, whatever their area or aim.

Jenis kerjasama yang disebut di atas adalah kerjasama internasional. OECD mendefinisikan kerjasama internasional sebagai konsep yang luas yang mencakup semua jenis kegiatan dilakukan bersama-sama dan dikoordinasikan oleh negara-negara berdaulat dua atau lebih dan/atau oleh organisasi internasional, pada bidang atau tujuan apapun.

Amey, Eddy, dan Ozaki. (2007:7) menyatakan kemitraan dan kerjasama secara tipikal melibatkan factor-faktor internal dan eksternal organisasional, iklim social-politik, konsern sumber daya manusia dan waktu.

Kontinum partnership digambarkan Aka (1993) sebagai berikut:

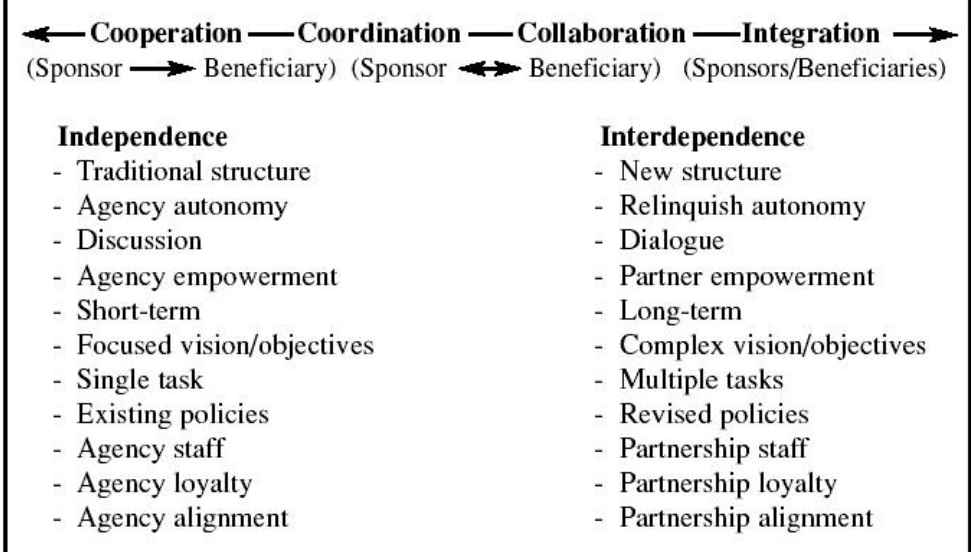


Jangkauan atau kontinum jenis kemitraan, tingkat atau kedalaman partisipasi oleh para mitra dapat bervariasi. Virolainen yang dikutip Häggman-Laitila A. \& Rekola L. (tth) menyatakan secara tradisional kemitraan/kerjasama antara perguruan tinggi dengan lapangan kerja telah diuji dari titik pandang kerjasama yang konsern dengan praktek klinis dan riset tesis.

\section{METODE PENELITIAN}

Penelitian ini menggunakan pendekatan kualitatif, dimana dalam analisisnya lebih banyak menekankan pada kata-kata dari obyek yang diteliti. Penelitian ini mengambil tempat di Fakultas Ilmu Tarbiyah dan Keguruan dikarenakan fakultas ini memiliki tempat pengembangan profesi yang banyak, terutama tempat pemakaian program Praktek Pengalaman Lapangan yang hampir mencakup madrasah/sekolah di eksKaresidenan Surakarta, tempat Kuliah Kerja Lapangan, dan kegiatan pemberdayaan sekolah/madrasah. Subyek dalam penelitian ini adalah ketua program studi di Fakultas Ilmu Tarbiyah dan Keguruan sebanyak 4 orang dan 3 orang pejabat rektorat. Teknik pengumpulan data yang digunakan dalam penelitian ini adalah sebagai berikut: Wawancara, Observasi, dan Dokumentasi. Keabsahan data dilakukan dengan cara triangulasi sumber dan metode secara bergantian. Teknik analisis data yang digunakan dalam penelitian ini menggunakan model interaktif. Artinya proses mengorganisasi dan merunut data ke dalam pola, kategori, dan satuan uraian dasar sehingga dapat ditemukan tema. Tema yang akan ditemukan adalah desain kerjasama.

\section{HASIL PENELITIAN DAN \\ PEMBAHASAN}

Hasil Penelitian

1. Realitas Pengelolaan Kerjasama
Realitas pengelolaan kerjasama dengan dunia eksternal dalam rangka peningkatan professionalitas civitas akademika selama ini di tingkat program studi masih bersifat top down karena ketua program studi tidak tahu sejak awal pembuatan draft naskah kerjasama. Kerjasama antara FITK dengan lembaga lain memiliki sejarah panjang dari tahun 1998 sampai saat ini. Ada yang mendasarkan pada payung hukum berupa naskah kerjasama (Memorandum of Understanding/MOU) dan adapula yang tidak memiliki dasar naskah kerjasama. Kepemilikan MOU belum dibuat naskah Memorandum of Agreement/MOA. Namun demikian kegiatan yang tidak dipayungi dasar hukum (baik $M O U$ maupun $M O A$ ) tetap berjalan karena pertimbangan kemanusiaan dan menjaga profesionalitas mahasiswa PPL sebagai calon guru dalam rangka meningkatkan 4 kompetensi guru, yaitu: kompetensi pedagogik, kompetensi sosial, kompetensi kepribadian, dan kompetensi professional. Dalam pengembangan profesi calon guru sekolah/madrasah dalam kerangka pengambangan kerjasama sudah berusaha meningkatkan penguasaan 4 kompetensi calon guru. Akan tetapi balikan dari FITK IAIN Surakarta kepada madrasah/sekolah tidak ada sehingga 4 kompetensi tidak ada upaya pengembangan. Kerjasama antara sekolah dan madrasah dengan 2 jurusan yang ada di FITK ada 2 perbedaan yaitu: Jurusan Bahasa dan Sastra sudah mulai ada kesepakatan kerjasama mulai tahun 2010 sedangkan Jurusan Tarbiyah baru mulai tahun 2011. Perbedaan kedua dalam naskah kerjasama Jurusan Bahasa dan Sastra sudah mencantumkah bentuk kerjasama yang lebih luas daripada Jurusan Tarbiyah yaitu Pelaksanaan P3M bersama, pelatihan, seminar, persiapan dan pelaksanaan kelas Bilingual, serta upaya standarisasi tenaga pendidik dan calon pendidik. Dengan perbedaan ini memungkinkan ada perluasan tindaklanjut dari sekedar pelaksanaan PPL. 


\section{Realitas Pengembangan Kerjasama}

Realitas pengembangan kerjasama dengan dunia eksternal dalam rangka peningkatan professionalitas civitas akademika di IAIN Surakarta selama ini terdapat tiga model kerjasama yang sedang dan sudah dirintis, yaitu:

1. Kerjasama yang dilakukan oleh IAIN Surakarta sebagai payung bagi kerjasama yang dilakukan oleh Fakultas/unit kerja yang ada di lingkungan IAIN Surakarta:

2. Kerjasama yang dilakukan oleh Fakultas/Unit Kerja di lingkungan IAIN Surakarta dengan melibatkan IAIN Surakarta.

3. Kerjasama yang dilakukan oleh Fakultas/Unit Kerja di lingkungan IAIN Surakarta secara mandiri.

Di tingkatan FITK IAIN Surakarta, kerjasama mendasarkan pada model 1 dan 3 . Pada model 1 terjadi karena status lembaga masih STAIN Surakarta. Sedangkan model 3 dilaksanakan karena status lembaga sudah berubah menjadi IAIN, sehingga Fakultas memiliki kewenangan untuk menandatangani MOU. Namun kerjasama yang dilakukan masih terbatas pada pelaksanaan PPL, sehingga diperlukan pengembangan ruang lingkup kerjasamanya.

Franz (2003:20) menemukan hal yang serupa bahwa di Austria mempunyai masalah utama pada pembagian kompetensi untuk pengembangan kerjasama di tingkat universitas antara dua jurusan yang berbeda. Jurusan Sain memegang kerjasama tingkat universitas, termasuk kegiatan penelitian dan kerjasama. Jurusan Hubungan Internasional bertanggung jawab atas kerjasama pembangunan inisiatif. Oleh karena itu semua kegiatan kemitraan eksklusif dibiayai dari anggaran Jurusan Sain, dengan pengecualian program beasiswa yang ditawarkan oleh Jurusan Hubungan Internasional. Di sisi lain untuk beasiswa keluar bagi peneliti atau mahasiswa dibayar oleh Jurusan Sain.

\section{Desain Pengembangan Kerjasama}

Pengembangan kerjasama kelembagaan dalam rangka peningkatan rofessionalitas civitas akademika di IAIN Surakarta memerlukan desain ulang agar tidak terbatas pada pelaksanaan PPL. Hal ini diperlukan dengan cara memperkuat kerjasama dengan sekolah mitra. Sekolah-sekolah mitra tidak hanya dijadikan tempat pelaksanaan PPL akan tetapi FITK dan sekolah/madrasah harus bersama-sama merumuskan kebutuhankebutuhan dan kompetensi apa yang diperlukan oleh seorang pendidik, selanjutnya keduanya bersama-sama untuk mencari solusi bisa melalui seminar, workshop dan lain-lain. Dengan kondisi demikian menjadikan ada kerjasama dalam peningkatan 4 kompetensi saling silang antara calon guru yang disiapkan oleh FITK IAIN Surakarta dengan pihak madrasah dan pihak madrasah mendapatkan pembinaan dan pendalaman 4 kompetensi. Kerjasama tersebut bisa juga menjadikan hidden curriculum dalam peningkatan 4 kompetensi tersebut, terutama kompetensi Kompetensi Kepribadian meliputi:

a. Bersikap inklusif, bertindak obyektif, serta tidak diskriminatif

b. Komunikasi dengan sesama guru, tenaga pendidikan, orang tua peserta didik, dan masyarakat

Disamping itu pula akan saling terbangun kompetensi professional para pelaku pendidikan, meliputi:

a. Penguasaan materi struktur konsep dan pola pikir keilmuan yang mendukung mata pelajaran yang diampu

b. Mengembangkan keprofesian melalui tindakan reflektif

Selain kerjasama dengan sekolah/madrasah mitra diperlukan kerjasama horisontal/sesama Perguruan tinggi. FITK harus memiliki hubungan yang sinergis dan harmonis dengan perguruan tinggi yang lain khususnya yang serumpun. Hal ini akan sangat berpengaruh dalam perumusan kurikulum dan 
penentuan kompetensi output yang diharapkan oleh fakultas sehingga tidak terjadi perbedaan yang signifikan antar output prodi yang ada di FITK IAIN Surakarta dengan prodi sejenis di perguruan tinggi lain. Kerjasama antar perguruan tinggi ini memungkinkan terjadinya joint research, student and lecturer exchange, pengabdian masyarakat bersama, dan lainnya.

Jika yang terjadi semacam ini maka seperti yang dinyatakan oleh Bjertness, Nijem, Husseini, Giacaman, HolmboeOttesen, dan Kristensen (2010): The InterUniversity Cooperation promotes intellectual cooperation through "twinning" and networking among higher education institutions and academics worldwide to permit the access, transfer and adaptation of knowledge within and across borders. Dengan demikian akan terbangun ketercepatan profesionalitas pada civitas akademika di semua perguruan tinggi melalui kerjasama kelembagaan.

\section{Pembahasan}

Dalam

mengimplementasikan

tridharma perguruan tinggi yang meliputi pendidikan/pengajaran, penelitian serta pengabdian kepada masyarakat diperlukan kerjasama dengan lembaga lain terutama sekolah/madrasah. Pengelolaan kerjasama dengan dunia eksternal di FITK masih bersifat top down karena yang tahu persis pimpinan dekanat dalam penyusunan draft awal sampai dengan penandatanganan naskah Memorandum of Understanding (MOU). Implementasinya belum dibuat naskah Memorandum of Agreement/MOA. Walaupun demikian isi dari MOU tetap diimplementasikan oleh Ketua Program Studi melalui kegiatan PPL, KKL, dan yang sejenis.

Hal ini dilakukan agar ada keterkaitan yang saling mendukung mutu masing-masing. Kerjasama PT dengan sekolah bisa mendorong mutu masing-masing Lembaga Pendidikan termasuk sumber daya manusianya. Kedua Lembaga yang mengimplementasikan 40 kerjasama bisa saling memanfaatkan dalam ranah akreditasi. Di tingkatan perguruan tinggi seperti yang tercantum dalam akreditasi program studi maupun perguruan tinggi pada model akreditasi 7 (tujuh) standar yang dikeluarkan BAN-PT disebutkan bahwa kerjasama merupakan satu kesatuan pada standar ketujuh yang menekankan pada penelitian, pengabdian kepada masyarakat dan kerjasama. Titik tekan kerjasama merupakan ruh akreditasi, semakin banyak kerjasama yang diimplementasikan akan semakin bernilai bagus pada Lembaga. Begitu pula Lembaga Pendidikan yang diajak kerjasama bisa saling give and take. Apalagi ketentuan baru tentang akreditasi program studi maupun perguruan tinggi pada model akreditasi 9 (sembilan) kriteria yang dikeluarkan BAN-PT menyebutkan aspek kerjasama melekat dengan tata kelola dengan tata pamong. Indikator yang harus ada ketika ada MOU harus muncul bukti berupa judul kegiatan, manfaat bagi program studi yang diakreditasi, dan bukti kerjasama. Bukti kerjasama dapat berupa Surat Penugasan, Surat Perjanjian Kerjasama (SPK), bukti-bukti pelaksanaan (laporan, hasil kerjasama, luaran kerjasama), atau bukti lain yang relevan. Bahkan diisyaratkan bahwa yang tidak dapat dijadikan bukti realisasi kerjasama adalah dokumen Memorandum of Understanding (MoU), Memorandum of Agreement (MoA), atau dokumen sejenis yang memayungi pelaksanaan kerjasama, (BAN-PT, 2019a:5). Disamping itu kerjasama menurut BAN-PT (BAN-PT, 2019b:18) harus memiliki aspek sebagai berikut: memberikan peningkatan kinerja tridharma dan fasilitas pendukung program studi yang diakreditasi, memberikan manfaat dan kepuasan kepada mitra serta menjamin keberlanjutan kerjasama dan hasilnya. Ketentuan ini menjadikan kerjasama sangat vital bagi penentu mutu masing-masing lembaga.

Dilihat dari kekentuan tersebut, Jurusan Bahasa dan Sastra sudah siap melaksanakan 
ketentuan baru akreditasi. Hal ini dikarenakan MOU mencantumkan bentuk kerjasama yang lebih luas yaitu Pelaksanaan P3M bersama.

Perguruan tinggi bisa mendayagunakan hasil penelitian dan pengabdian kepada masyarakat. Sementara sekolah/madrasah bisa terbantu dalam peningkatan mutu guru. Penelitian ini searah dengan temuan Stern (2004:49) bahwa pengembangan profesional guru terbantu dengan adanya kerjasama dengan perguruan tinggi. Guru semakin terlibat dalam organisasi sekolah dan meningkatnya komunikasi professional diantara para guru.

Realitas pengembangan kerjasama FITK mengacu pada model 1 dan 3 masih terbatas pada kegiatan Program Pengalaman Lapangan (PPL). Bagi jurusan Bahasa dan Sastra semestinya perlu dikembangkan pada semua ranah tridharma PT sehingga tidak terbatas pada kegiatan PPL. Bagi Jurusan Tarbiyah perlu memperluas aspek kerjasamanya sehingga bisa mengembangkan mahasiswa, serta sumber daya manusia yang dimiliki.

Desain Pengembangan kerjasama kelembagaan diperlukan oleh FITK maupun IAIN Surakarta, sehingga tidak terbatas pada pelaksanaan PPL. Langkah yang bisa ditempuh melalui tahapan cara pemetaan user, memperkuat mitra sekolah yang tidak hanya berfokus pada pelaksanaan PPL akan tetapi belum terjadi give and take antara madrasah/sekolah dengan Fakultas di IAIN Surakarta.

\section{SIMPULAN DAN SARAN}

\section{Simpulan}

Berdasarkan temuan dan pembahasan, dapat disimpulkan. Pertama. Realitas pengelolaan kerjasama dengan dunia eksternal dalam rangka peningkatan profesionalitas civitas akademika selama ini di tingkat program studi masih bersifat top down ketika merencanakan draft naskah kerjasama.
Kerjasama antara sekolah dan madrasah dengan 2 jurusan yang ada di FITK ada 2 perbedaan yaitu: Jurusan Bahasa dan Sastra sudah mulai ada kesepakatan kerjasama mulai tahun 2010 sedangkan Jurusan Tarbiyah baru mulai tahun 2011. Perbedaan kedua dalam naskah kerjasama Jurusan Bahasa dan Sastra sudah mencantumkah bentuk kerjasama yang lebih luas daripada Jurusan Tarbiyah yaitu Pelaksanaan P3M bersama, pelatihan, seminar, persiapan dan pelaksanaan kelas Bilingual, serta upaya standarisasi tenaga pendidik dan calon pendidik. Dengan perbedaan ini memungkinkan ada perluasan tindaklanjut dari sekedar pelaksanaan PPL. Namun keduanya ada persamaanya yaitu kerjasamanya masih terbatas pada pelaksanaan PPL.

Kedua. Realitas pengembangan kerjasama dengan dunia eksternal dalam rangka peningkatan professionalitas civitas akademika di IAIN Surakarta selama ini berawal dari kerjasama tanpa payung hukum menjadi ada payung hukum. Hasil lain menunjukkan Kerjasama yang dilakukan oleh IAIN Surakarta dijadikan sebagai payung bagi kerjasama yang dilakukan oleh Fakultas/unit kerja yang ada di lingkungan IAIN Surakarta; kerjasama yang dilakukan oleh Fakultas/Unit Kerja di lingkungan IAIN Surakarta dengan melibatkan IAIN Surakarta; kerjasama yang dilakukan oleh Fakultas/Unit Kerja di lingkungan IAIN Surakarta secara mandiri.

Desain pengembangan kerjasama kelembagaan dalam rangka peningkatan professionalitas civitas akademika di IAIN Surakarta perlu dikembangkan dengan cara pemetaan user, memperkuat mitra sekolah yang tidak hanya berfokus pada pelaksanaan PPL. Kerjasama Horisontal/Sesama Perguruan tinggi Islam belum terbangun walaupun sebenarnya hal ini akan sangat berpengaruh dalam perumusan kurikulum dan penentuan kompetensi output yang diharapkan oleh fakultas sehingga tidak terjadi perbedaan yang 
signifikan antar output prodi di FITK IAIN Surakarta dengan prodi lain di PT lain.

\section{Saran}

Berdasarkan hasil penelitian, dapat disampaikan saran agar kerjasama dapat dilakukan berdasarkan aspirasi dari bawah (bottom up) sehingga lebih membuka peluang bentuk kerjasama, desain kerjasama perlu disepakati bersama sehingga memungkinkan setiap kegiatan bekerjasama dengan lembaga lain yang dipayungi dasar hukum dalam bentuk naskah kerjasama (MoU), Naskah Kerjasama harus ditindaklanjuti dalam bentuk tindakan-tindakan konkrit sehingga ada saling memberdayakan antara 2 lembaga, serta kerjasama dilakukan dengan lembaga lain yang lebih variatif seperti perguruan tinggi agama Islam, lembaga pendidikan nonformal, maupun lembaga non pendidikan serta kerjasama dengan perguruan tinggi luar negeri.

\section{DAFTAR PUSTAKA}

Aka, Karen Y. (1993). Developing Effective Educational Partnerships: The Why, What, and How. http://www.prel.org/products/products/ Partnerships.pdf

Amey, Marilyn J., Eddy, Pamela and Ozaki, L. C. Casey. (2007). Demands for Partnership and Collaboration in Higher Education: A Model. New Directions For Community Colleges, no. 139, Fall 2007 (C) 2007 Wiley Periodicals, Inc. Published online in Wiley InterScience. (www.interscience.wiley.com) - DOI: $10.1002 /$ cc. 288

Austin, J. E. (2000a). The collaboration challenge: How nonprofits and businesses succeed through strategic alliances. San Francisco: Jossey-Bass.

Bailey, Fiona \& Dolan, Anne M. (2011). The Meaning of Partnership in Development: Lessons in Development
Education', Policy \& Practice: A Development Education Review, Vol. 13, Autumn 2011, pp. 30-48, available: http://www.developmenteducationrevie w.com/issue13-focus2

BAN-PT. (2019a). Panduan Penyusunan Laporan Kinerja Program Studi. Jakarta : BAN-PT

BAN-PT. (2019b). Panduan Penyusunan Laporan Evaluasi Diri. Jakarta : BANPT

Bjertness, Espen Nijem, Khaldoun, Husseini, Abdullatif, Giacaman, Rita, HolmboeOttesen, Gerd and Kristensen, Petter. (2010). 15 years of cooperation in research and higher education between the Faculty of Medicine, University of Oslo, and Palestinian institutions. http://www.thelancet.com/health-inthe-occupied-palestinian-territory-2010

Beneitone, Pablo. (2003). Introduction: Some ideas about University Development Co-operation in Pablo Beneitone, Susan Höivik, Nadia Molenaers, Andreas Obrecht, and Robrecht Renard. (2003). University Development Co-operation Models of Good Practice. http://www. humanitariannet.deusto.es/publica/PUB LICACIONES_PDF $/ 11 \% 20$ Models $\% 2$ 0of $\% 20$ Good $\% 20$ Prac.pdf

Czajkowski, Joyce M.. (2007). Leading Successful interintitutional collaboration. Using The Collaboration Succes Measurement Model. http://www.chairacademy.com/confere nce/2007/papers/leading_successful_int erinstitutional_collaborations.pdf

Franz, Margit. (2003). Models of Good Practice of International Co-operation - Austria. in Pablo Beneitone, Susan Höivik, Nadia Molenaers, Andreas Obrecht, and Robrecht Renard. (2003). 
University Development Co-operation Models of Good Practice. http://www.humanitariannet.deusto.es/ publica/PUBLICACIONES_PDF/11\% 20Models\%20of\%20Good\%20Prac.pdf

Goetsch, David L. and Davis, Stanley B. (2006). Quality management for organizational excellence : introduction to total quality; Upper Saddle River, N.J. : Pearson

Himmelman, Arthur Turovh. (1996). On The Theory and Practice of Transformational Collaboration: Cpllaboration As A Bridge From Social Service to Social Justice. London: Sage Publications, 1996, pp. 19-43.

Häggman-Laitila A. \& Rekola L. tth. Partnership between higher education and working life - Developing an action model by means of action research.
Peraturan Pemerintah Nomor 30 Tahun 1990 tentang Pendidikan Tinggi

Stern, Thomas. (2004). Cooperation between Schools and Universities as a Catalyst for the Professional Development of Teachers. http://www.hbcse.tifr.res.in/episteme/e pisteme-1/allabs/stern.pdf

Unesco. (1998). World Declaration On Higher Education For The Twenty-First Century: Vision AndAction http://www.unesco.org/education/educ prog/wche/presentation.htm

Vasilyan, Syuzanna. (2004). The Policy of 'Regional Cooperation in the South Caucasus'. Centro Argentino de Estudios Internacionales www.caei.com.ar

Welch, M. (1998). Collaboration: Staying on the bandwagon. Journal of Teacher Education 49, no. 1 (Jan./Feb.): 26-38. Accessed Apr. 24, 2004, http://web7.infotrac.galegroup.com. 